\title{
Grain Harvesting Strategies to Minimize Grain Quality Losses Due to Fusarium Head Blight in Wheat
}

Jorge David Salgado, Matthew Wallhead, Laurence V. Madden, and Pierce A. Paul, Department of Plant Pathology, Ohio State University and the Ohio Agricultural Research and Development Center, Wooster 44691

\begin{abstract}
Salgado, J. D., Wallhead, M., Madden, L. V., and Paul, P. A. 2011. Grain harvesting strategies to minimize grain quality losses due to Fusarium head blight in wheat. Plant Dis. 95:1448-1457.

Fusarium head blight (FHB) reduces wheat grain yield and quality, leading to price discounts due to Fusarium-damaged kernels (FDK), deoxynivalenol (DON) contamination of grain, and reduced test weight (weight per unit volume of grain). Experiments were conducted to determine whether changing combine harvester configurations to differentially remove diseased kernels affected the yield and quality of grain harvested from plots with different mean levels of FHB index (IND, mean proportion of diseased spikelets per spike), achieved with inoculations at different spore densities. Plots were harvested using four combine configurations, with $\mathrm{C} 1$ being the standard, set at a fan speed of $1,375 \mathrm{rpm}$ and a shutter opening of $70 \mathrm{~mm}$, and C2, C3, and C4 regulated to fan speeds and shutter openings of $1,475 \mathrm{rpm}$ and 70 $\mathrm{mm}, 1,475 \mathrm{rpm}$ and $90 \mathrm{~mm}$, and $1,375 \mathrm{rpm}$ and $90 \mathrm{~mm}$, respectively. C3 and C4 consistently had significantly lower mean arcsine-transformed FDK and log-transformed DON and higher mean test weight than did $\mathrm{C} 1$. However, $\mathrm{C} 3$ and $\mathrm{C} 4$ also resulted in significantly lower mean amounts of harvested grain than did $\mathrm{C} 1$. The estimated mean responses to combine configuration were consistent across a range of

based on the incidence of FDK, DON, and test weight, and the mean values found in the current investigation for these grain-quality variables, configurations $\mathrm{C} 2, \mathrm{C} 3$, and $\mathrm{C} 4$ resulted in between $\$ 10$ and $40 / \mathrm{t}$ lower estimated grain price discounts than $\mathrm{C} 1$, with the lowest discounts corresponding to $\mathrm{C} 3$ and $\mathrm{C} 4$. Using the discount values, a range of grain prices, and the mean yield values from this investigation, estimated gross cash income $(\mathrm{GCI}$; mean estimated yield $\times$ grain price adjusted for discounts due to inferior quality) was generally higher for grain harvested with $\mathrm{C} 2$ and $\mathrm{C} 4$ than with $\mathrm{C} 1$ or $\mathrm{C} 3$, with $\mathrm{C} 4$ being the most consistent across a range of IND levels (5 to 35\%) and grain prices ( $\$ 118$ to $276 / \mathrm{t}$ ). For all modified configurations, the greatest increases in GCI over $\mathrm{C} 1$ were observed at the lowest tested grain price, and the improvement of GCI over $\mathrm{C} 1$ increased with increasing IND up to the highest disease level tested. Thus, these results showed that, when harvesting grain from FHB-affected fields, the improvement in grain quality and reduction in price discounts with a combine adjustment could be great enough to counteract the reduction in harvested grain that results from the adjustment..
\end{abstract} mean IND levels (5 to $35 \%$ ). Using a common price discount schedule
Fusarium head blight (FHB) of wheat (Triticum aestivum L.) is a serious disease in most wheat-producing regions of the world. Fusarium graminearum Schwabe (teleomorph: Gibberella zeae) is the predominant causal pathogen of FHB in the United States and Canada (20,26). Under wet, humid conditions $(13,20)$, infection of wheat spikes may cause significant grain yield and quality losses due to poor grain fill, high percentage of damaged (scabby) kernels, and low test weights (weight per unit volume) $(2,17,20,25)$. In addition, infected grain is usually contaminated with deoxynivalenol (DON), a mycotoxin produced by the pathogen $(23,44)$. DON, also known as vomitoxin, represents a health threat to humans and livestock (33); therefore, mycotoxin-contaminated grain is either rejected or priced down at elevators $(2,20)$.

Management of, and mitigation of losses due to, this diseasetoxin complex are usually achieved through the implementation of pre- and post-harvest strategies (12). Common preharvest management practices include the use of resistant cultivars, fungicide application, crop rotation, and tillage $(8,12,34,46)$. Resistance is the most efficient and economically sound way of managing FHB but no cultivar is immune to this disease and even the most resistant cultivars may become infected under favorable weather condi-

Corresponding author: P. A. Paul, E-mail: paul.661@ osu.edu

Any opinions, findings, conclusions, or recommendations expressed in this publication are those of the authors and do not necessarily reflect the view of the United States Department of Agriculture.

Accepted for publication 1 July 2011.

doi:10.1094/PDIS-04-11-0309

(C) 2011 The American Phytopathological Society tions $(2,22,36)$. Chemical control as a preventive strategy, particularly the timely application of triazole-based fungicides, has shown positive results, reducing FHB and DON and minimizing yield and quality losses $(28,29,32,34)$. However, the effects of cultivar resistance and fungicide on FHB and DON are highly variable, depending on the weather and other environmental factors related to the locations where they are implemented $(21,28,29,32,35,41)$.

Agronomic practices such as crop rotation and tillage also contribute to minimizing FHB development by reducing the amount of in-field inoculum carried over from one growing season to another (7). However, widespread use of reduced- and no-till cropping practices for soil conservation purposes has prevented these approaches from being as effective as they could be at the individual field level in most areas $(1,46)$, because spores of $F$. graminearum can be easily blown from one field to another (18). Moreover, the effects of crop rotation and tillage on FHB and DON are influenced by weather conditions, the crops used in the rotation, and other disease-management and agronomic practices $(7,8,12,16$, 40,46). The combination of cultivar resistance, fungicide application, and agronomic practices has generally been more effective than any individual strategy at reducing FHB and DON $(19,42)$. However, when conditions for disease development are highly favorable, DON contamination and grain quality reduction cannot be avoided, even when integrated management strategies are implemented $(19,41,42)$.

In addition to control measures implemented in the field, other methods for mitigating losses due to FHB and contamination of food products with mycotoxins have been implemented post-harvest (12). For instance, grain blending is a standard practice that consists of diluting contaminated grain using clean grain (6). Other methods include using screening and aspiration techniques to separate diseased grain from healthy grain based on size, weight, and density $(12,38)$; optical sorting or spectrometry to classify and 
separate grain based on kernel morphology and color $(4,6,12,43)$; and chemical and physical procedures to remove mycotoxins, contaminated grain, and infected particles $(12,39,45)$. However, these methods are not always effective and their implementation is not always practical and economical $(6,12)$.

Grain harvesting strategies have also been proposed as a way of reducing losses due to FHB and DON. Diseased kernels are often lighter than healthy kernels and, as such, can be removed during harvest $(12,20)$. Research has shown that DON levels are positively correlated with Fusarium-damaged kernels (FDK) (proportion of visually damaged and whitish-pink colored kernels) and other visual estimates of FHB $(3,30,31)$; therefore, reducing FDK during harvest generally leads to reduction in DON. For instance, reducing combine harvester travel speed helps to separate and remove infected, lightweight kernels by increasing air blast time (H. Spieser and A. W. Schaafsma, personal communication). Similarly, increasing fan speed helps to remove damaged, lightweight kernels, reducing the level of toxin contamination of the grain lot $(11,12)$. However, one potential downside of changing the configurations of a combine harvester is that this could lead to removal of healthy kernels (H. Spieser and A. W. Schaafsma, personal communication) and result in lower total yield per unit land area.

Although seemingly very intuitive, based on the fact that diseased kernels are lightweight and may be easily blown out of the combine during harvest (20), the efficacy and benefit of modifying combine harvester configurations to improve the overall quality of grain harvested from FHB-affected fields has not been systematically tested. When FHB levels are high, producers are often faced with the decision of whether to harvest as much grain as possible at standard combine fan speed or increase fan speed to remove as many of the diseased kernels as possible (20). However, no specific recommendations currently exist as to what set of combine configuration changes would work best in terms of improving grain quality while at the same time minimizing excessive removal of healthy grain across a range of FHB levels. The objectives of this study were to (i) evaluate the influence of varying combine harvester fan speed and airflow on FDK, DON contamination, test weight (TW), and yield of soft-red winter wheat grain harvested from FHB-affected plots; (ii) determine whether the effects of harvester configuration on grain yield and quality were influenced by FHB intensity; and (iii) conduct a cost-benefit assessment to determine whether the gain in grain quality (reductions in FDK, DON contamination, and increase in TW) was sufficient to offset yield loss resulting from modified harvester configurations.

\section{Materials and Methods}

Plot establishment, inoculation, and disease assessment. Wheat plots of susceptible soft red winter wheat 'Hopewell' were planted on 25 September 2008 and 06 October 2009 at Snyder Farm, Ohio Agricultural Research and Development Center, near Wooster. All plots were established in fields previously planted with oat and managed according to standard agronomic practices for winter wheat in Ohio (27). Prior to planting, fields were moldboard plowed, disked, harrowed, and then leveled with a cultipacker roller. In total, 60 plots (each 1.5 by $6 \mathrm{~m}$ ) were planted in each experiment, at a seeding rate of $4 \times 10^{6}$ seeds/ha. The experimental design was a randomized complete block, with three replicate blocks and combine harvester configuration and inoculum density in a split-plot arrangement. Configuration was the whole plot and inoculum density the subplot.

Inoculum was prepared using a mixture of 10 highly aggressive isolates of $F$. graminearum previously collected from naturally infected wheat spikes grown in Ohio. Isolates were grown on mung bean agar (MBA) (40 g of mung bean and $20 \mathrm{~g}$ of Bacto agar per liter of distilled water) for macroconidia production and on carrot agar (CA) (400 g of diced carrot and $20 \mathrm{~g}$ of Bacto agar per liter of distilled water) for ascospore production. Plates were incubated at room temperature $\left(18^{\circ} \mathrm{C}\right.$, night and $22^{\circ} \mathrm{C}$, day) for 7 to 10 days under ultraviolet and fluorescent lights, with a 12 -h photoperiod. MBA plates were harvested by adding 8 to $10 \mathrm{ml}$ of sterile, dis- tilled water and gently scrapping the surface of cultures with a rubber policeman to dislodge macroconidia. After 7 to 10 days, perithecia formation was induced on CA plates by removing the mycelial mat with a bent glass rod as described by Engle et al (10). CA plates were then incubated for an additional 10 to 14 days, after which ascospores were harvested as described above.

The concentration of both macroconidia and ascospores was determined using a hemocytometer (Reichert-Bright Line; Hausser Scientific, Horsham, PA) and then adjusted to the final inoculum densities by adding distilled water and Tween (2\%). Five different inoculum densities $\left(0,1.5,3,4.5\right.$, and $6 \times 10^{4}$ spores $\left./ \mathrm{ml}\right)$ were prepared using a 1:1 mixture of ascospores and macroconidia of the 10 isolates. All inoculations were done at early anthesis (Feekes 10.5.1) using a back-pack sprayer (R\&D Sprayers, Opelousas, LA) equipped with nozzles that allowed the sprayer to deliver $32 \mathrm{ml} / \mathrm{m}$ of row per second. Inoculations were done on 27 May 2009 and 25 May 2010, during the evening hours.

Disease assessments were made on 22 June 2009 and 17 June 2010 at approximately the soft dough growth stage (Feekes 11.2). Five groups of 20 spikes were arbitrarily selected in each plot and scored for FHB incidence (INC) and index (IND) based on visual symptoms. INC was recorded as the mean proportion of diseased spikes (number of spikes with nonzero severity divided by the total number of spikes sampled), whereas IND was recorded as the mean proportion of diseased spike area (spikelets) (sum of the proportion of diseased spikelets per spike divided by the total number of spikes sampled, including those with zero severity).

Combine configurations, grain harvest, and sampling. Plots were harvested on 14 July 2009 and 17 July 2010, when grain moisture levels dropped to approximately 13\%. An ALMACO SPC20 (ALMACO, Nevada, IA) research plot combine harvester was used in both years. Prior to harvest, the combine was calibrated on noninoculated, FHB-free plots of Hopewell. Harvest travel speed was kept constant between 4.8 and $5.3 \mathrm{~km} / \mathrm{h}$ in both years, and threshing, separation, and cleaning devices, along with fan speed (airflow speed) and shutter opening (regulates the volume of air flowing through the combine), were regulated to minimize excessive removal of healthy kernels (G. Nielsen, personal communication). This was done by walking behind the combine after each set of adjustments and observing the amount of grain discarded. The configuration that resulted in the lowest level of grain loss during harvest was selected as the standard (manufacturer-recommended configuration) $(\mathrm{C} 1)$. The fan speed for $\mathrm{C} 1$ was measured using a digital tachometer (Nidec-Shimpo America Corp., Itasca, IL) and the manually adjusted shutter opening for C1 was recorded. These were $1,375 \mathrm{rpm}$ for fan speed and $70 \mathrm{~mm}$ for the shutter opening.

With the standard configuration as the reference, the combine was regulated to obtain three additional combinations of fan speeds and shutter openings, for a total of four configurations. The four configurations were $\mathrm{C} 1$, the standard configuration, with a fan speed of 1,375 rpm and a shutter opening of $70 \mathrm{~mm}$; C2, high fan speed $(1,475 \mathrm{rpm})$ with standard shutter opening of $70 \mathrm{~mm}$; 3 , high fan speed $(1,475 \mathrm{rpm})$ and a wide shutter opening of $90 \mathrm{~mm}$; and $\mathrm{C} 4$, standard fan speed $(1,375 \mathrm{rpm})$ and a wide shutter opening of $90 \mathrm{~mm}$. All other threshing, separation, and cleaning devices were held constant at the standard configuration. At the time of harvest, the air flow at the back end of the combine was estimated for each configuration using a Davis WindScribe Ultrasonic Handheld Wind Meter (Davis Instrument, Hayward, CA). The estimated mean values were $13.51 \mathrm{~km} / \mathrm{h}$ for $\mathrm{C} 1,21.24 \mathrm{~km} / \mathrm{h}$ for $\mathrm{C} 2,29.93$ $\mathrm{km} / \mathrm{h}$ for $\mathrm{C} 3$, and $27.03 \mathrm{~km} / \mathrm{h}$ for $\mathrm{C} 4$, based on the average of two readings taken immediately before and after harvesting plots assigned to each configuration. Readings were taken by holding the wind meter at the back end of the combine where the straw is expelled.

Grain yield $(\mathrm{kg} / \mathrm{ha}), \mathrm{TW}\left(\mathrm{kg} / \mathrm{m}^{3}\right)$, and moisture $(\%)$ content were determined for each subplot directly on the combine, and grain samples were collected and visually rated for FDK (percentage of shriveled and whitish-pink kernels, based on a diagrammatic rating 
scale; 9). Samples were ground using a Laboratory Mill (Model LM 3303; Perten Instruments Inc., Springfield, IL) and 10-g subsamples were sent for DON analysis at the U.S. Wheat and Barley Scab Initiative-funded DON-testing laboratory at the University of Minnesota by gas chromatography mass-spectrometry (GC/MS). DON was extracted by shaking each sample of ground grain in a mixture of acetonitrile and water $(18: 16, \mathrm{vol} / \mathrm{vol})$ for an hour. The extract was then passed through a column packed with C18 and aluminum oxide (1:3) and an aliquot of the filtrate was evaporated to dryness under nitrogen and derivatized by the silylating reagent (TMSI/TMCS 100:1; Pierce Chemical Co., IL) for GC/MS analysis (Shimadzu GCMS-QP2010, Shimadzu Corporation, Kyoto,

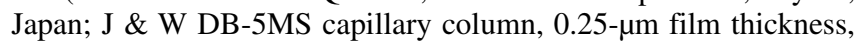
0.25-mm i.d., and $30 \mathrm{~m}$ ) (Y. Dong, personal communication).

Data analysis. Mixed-model analysis of variance and covariance. Prior to the analysis, responses recorded as percentages or proportions (FHB INC, IND, and FDK) were arcsine transformed and DON data $\log$ transformed to stabilize variances. There were four replicate plots of each inoculum density in each block; therefore, for IND and INC responses measured before the imposition of the whole-plot factor (combine harvester configurations), the experimental design was considered a replicated randomized complete block, commonly referred to as a generalized randomized block design (this is because, before harvest, all whole-plot levels were the same). For all post-harvest responses, the experimental design was a randomized complete block, with a split-plot arrange-
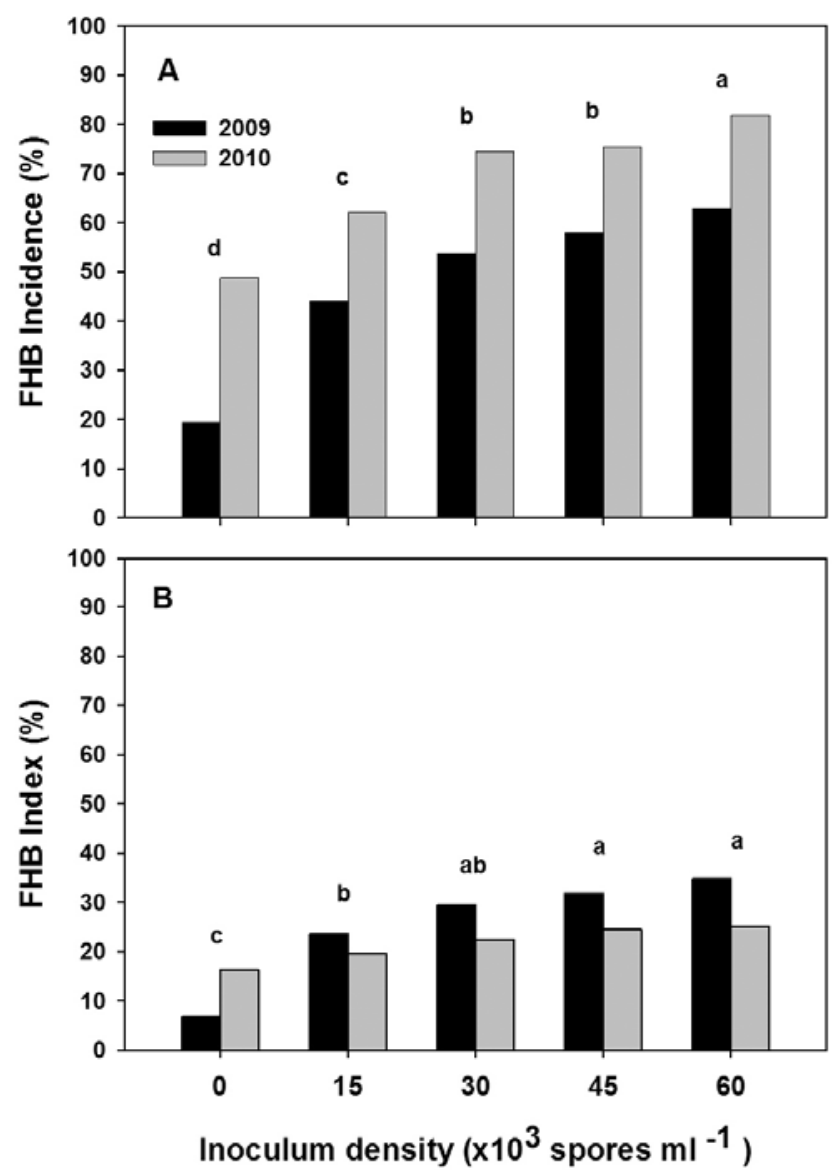

Fig. 1. Mean Fusarium head blight (FHB) $\mathbf{A}$, incidence and $\mathbf{B}$, index for wheat plots inoculated with five different Fusarium graminearum inoculum densities in 2009 and 2010. Incidence was recorded as the mean proportion of diseased spikes (number of spikes with nonzero severity divided by the total number of spikes sampled), whereas index was recorded as the mean proportion of diseased spikelets per spike (sum of the proportion of diseased spikelets per spike divided by the total number of spikes sampled, including those with zero severity). Each bar represents the mean of three replications. Inoculum densities (pairs of bars) with the same letters are not significantly different from each other based of $F$ tests from linear mixed-model analysis of pooled arcsine-transformed data. ment of combine configuration and inoculum density. For arcsinetransformed incidence (arcINC) and index (arcIND), the effect of inoculum density, and for arcsine-transformed FDK (arcFDK), logtransformed DON $(\log \mathrm{DON}), \mathrm{TW}$, and grain yield, the effects of combine configuration, inoculum density, and their interactions were determined using linear mixed models (15). Combine configuration and inoculum density were treated as qualitative factors and fixed effects in the analysis. Block, year (YEAR), and all interactions involving these variables were considered random effects.

For the analyses of arcFDK, $\log$ DON, TW, and yield, FHB IND was included in the models as a continuous covariate. All analyses were done using PROC MIXED of SAS (SAS Institute, Cary, NC). Fixed effects were evaluated with $F$ tests whereas random effects were evaluated with standard normal test statistics.

Cost/benefit assessment. Using the mixed model fitted to different response variables with IND as a covariate, predicted yield, TW, $\log$ DON, and arcFDK were determined for three selected IND values $(5,20$, and $35 \%$ ) for each of the four combine configurations. Predicted DON (ppm) and FDK (\%) were determined by backtransforming $\operatorname{logDON}$ and arcFDK, respectively. These predicted responses were then used along with a range of grain prices and price discounts to evaluate the potential cost and benefit of using modified combine configurations to harvest grain from FHBaffected plots. Gross cash income (GCI) was estimated for grain prices of $\$ 118$ (\$3/bushel), \$197 (\$5/bushel), and \$276 (\$7/bushel) per metric ton from predicted grain yield and TW and predicted back-transformed FDK and DON at 5, 20, and 35\% disease IND as

$G C I=Y \cdot(P-d c t)$

where $G C I$ ( $\$ / \mathrm{ha})$ is from the sale of wheat grain (assuming that the sale of grain is the only source of cash income), $Y$ is grain yield (t/ha), $P$ is grain price $(\$ / t)$, and $d c t=$ total price discount $(\$ / t$; reduction in the price per unit weight). The price discount is given by

$d c t=t w l+f d k l+d o n l$

where $t w l, f d k l$, and $d o n l$ represent individual estimated price discounts due to TW below, and FDK and DON contamination above, thresholds established by grain elevators. Because FDK, DON, and TW are known to be correlated with disease IND in the field (30), $t w l, f d k l$, and $d o n l$ are all statistically related to IND. We considered a range of price discounts typically found (M. McMullen, personal communication) for each of the three given grain prices, and considered a range of mean yield $(Y)$, TW, FDK, and DON values that were representative of those found for the different combine configurations in this study.

\section{Results}

FHB intensity and weather conditions. In both 2009 and 2010 , FHB INC and IND increased with inoculum density, reaching the highest levels in plots inoculated with $60 \times 10^{3}$ spores $/ \mathrm{ml}$ (Fig. 1). Mean INC and IND ranged from 19.5 to 62.9 and 6.7 to $34.8 \%$, respectively, in 2009, and from 48.7 to 81.9 and 16.2 and $25.1 \%$, respectively, in 2010. Compared with 2009, more frequent rainfall occurred during and prior to anthesis in 2010, resulting in higher levels of natural infection in the second year, as indicated by the level of disease in the noninoculated plots (Fig. 1). Total rainfall during the days leading up to anthesis (the last 2 weeks of May) was $18 \mathrm{~mm}$ in 2009 and $32 \mathrm{~mm}$ in 2010, and average relative humidity for the same period was $61.6 \%$ in 2009 and $81.6 \%$ in 2010 . However, the overall level of FHB IND (average percent spike area diseased) was lower in 2010 than in 2009.

Based on results from linear mixed-model analysis (15) of pooled arcsine-transformed data, the effect of inoculum density was statistically significant for both INC and IND but the effect of YEAR was not (Table 1). Uninoculated (control) plots had significantly $(P<0.05)$ lower arcINC and arcIND than all inoculated plots (Fig. 1). Among the inoculated plots, both INC and IND were significantly higher (on the arcsine-transformed scale) in plots receiving the highest inoculum densities (45 and $60 \times 10^{3}$ 
spores $/ \mathrm{ml})$ than in those receiving the lowest density $\left(15 \times 10^{3}\right.$ spores/ml) (Fig. 1). Mixed-model regression analysis revealed a highly significant $(P<0.05)$ positive linear relationship between log-transformed inoculum density (continuous variable) and both arcINC and arcIND (data not shown).
Inoculum density and combine configuration effects on harvested grain quality and yield. FDK, DON contamination, TW, and grain yield varied with inoculum density and combine configuration in 2009 and 2010 (Fig. 2). For each of these variables, similar trends with inoculum density were observed in both years, with

Table 1. Probability values (significance levels: $P$ ) from linear mixed model analyses to determine the effects of year, Gibberella zeae inoculum density and combine harvester configuration on arcsine-transformed Fusarium head blight (FHB) incidence (arcINC), index (arcIND), and Fusarium-damaged kernel (arcFDK), log-transformed deoxynivalenol contamination of harvested grain $(\log \mathrm{DON})$, test weight $(\mathrm{TW})$, and grain yield

\begin{tabular}{lccccrr}
\hline & \multicolumn{7}{c}{ Dependent variable } \\
\cline { 2 - 7 } Factors $^{\mathbf{b}}$ & arcINC & arcIND & arcFDK & logDON & TW & Yield \\
\hline YEAR & 0.482 & 0.575 & 0.491 & 0.480 & 0.995 & 0.486 \\
INOC & $<0.001$ & $<.001$ & 0.004 & 0.047 & 0.307 & 0.836 \\
CONFIG & $\ldots$ & $\ldots$ & $<0.001$ & $<0.001$ & 0.001 & $<0.001$ \\
INOC $\times$ CONFIG & $\ldots$ & $\ldots$ & $<0.001$ & $<0.001$ & 0.003 & 0.013 \\
IND & $\ldots$ & $\ldots$ & $<.025$ & 0.092 \\
\hline
\end{tabular}

${ }^{a}$ INC = percentage of diseased spikes in a sample, IND = percentage of diseased spikelets per spike, FDK = percentage of visually diseased kernels, DON $=$ deoxynivalenol content of grain in ppm, TW $=$ grain weight per unit volume $\left(\mathrm{kg} / \mathrm{m}^{3}\right)$, and Yield $=$ grain yield $(\mathrm{kg} / \mathrm{ha})$. Probability values for fixed effects (inoculum density [INOC], configuration [CONFIG], and INOC $\times$ CONFIG) were based on $F$ tests, whereas the probability value for YEAR (the random effect) was determined based on standard normal tests.

${ }^{b}$ INOC $=$ inoculum density $\left(0,15,30,45\right.$, and $60 \times 10^{3}$ spores $\left.\mathrm{ml}^{-1}\right) ; \mathrm{CONFIG}=$ combine harvester configuration $(\mathrm{C} 1=$ the standard configuration, with a fan speed of $1,375 \mathrm{rpm}$ and a shutter opening of $70 \mathrm{~mm} ; \mathrm{C} 2=\mathrm{a}$ high fan speed of $1,475 \mathrm{rpm}$ with a shutter opening of $70 \mathrm{~mm}$; $\mathrm{C} 3=\mathrm{a}$ fan speed of 1,475 rpm and a shutter opening $90 \mathrm{~mm}$; and $\mathrm{C} 4=\mathrm{a}$ fan speed of $1,375 \mathrm{rpm}$ and a shutter opening of $90 \mathrm{~mm}$ ); IND = FHB index as a continuous covariate.
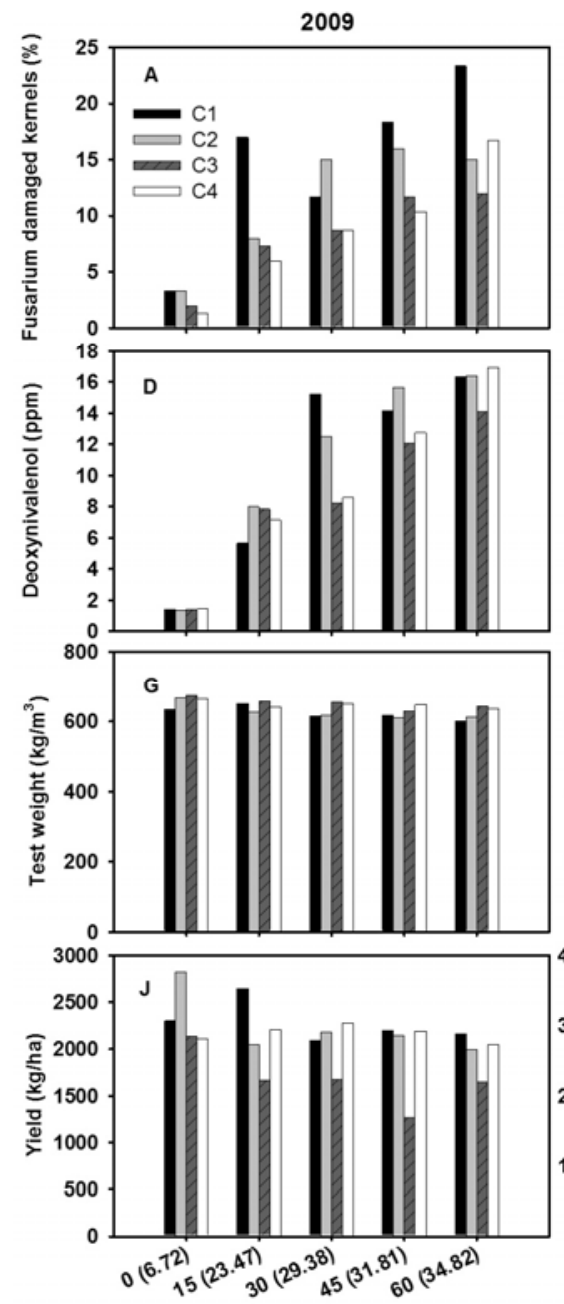

2010

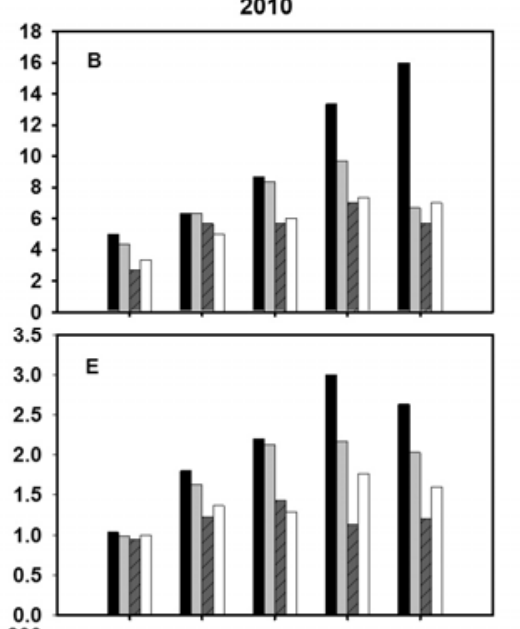

800

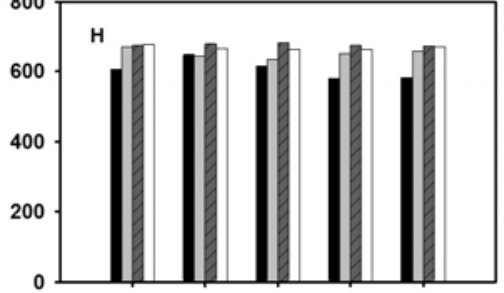

4000

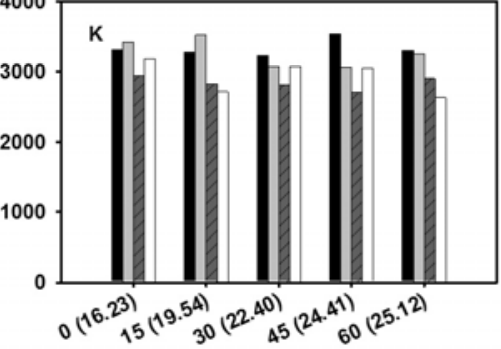

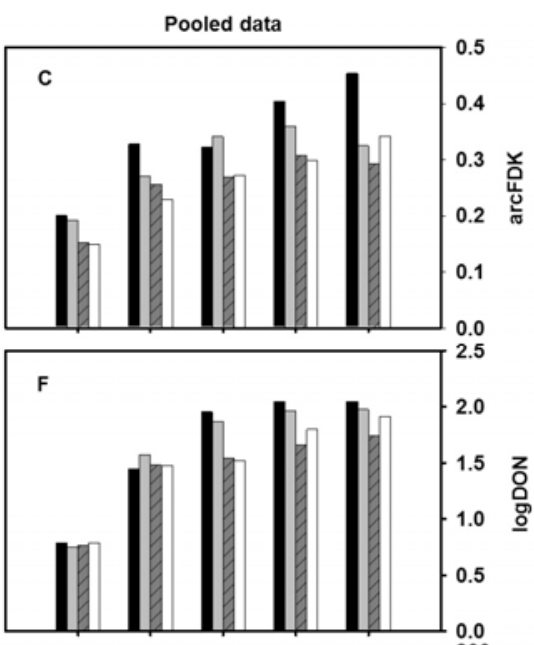
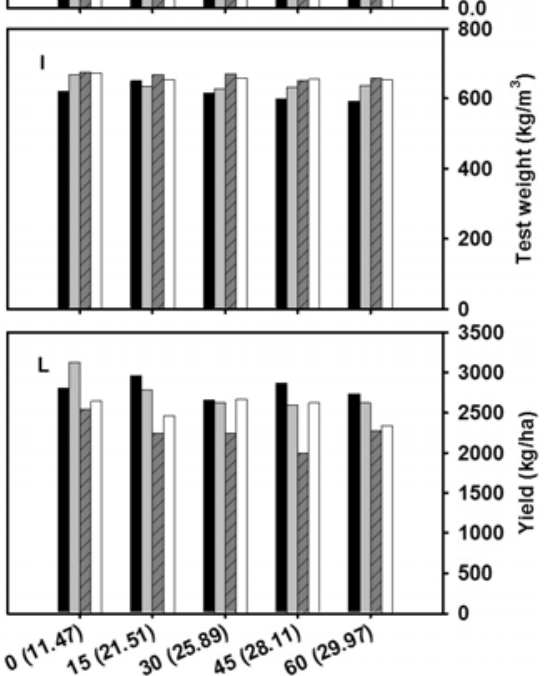

Inoculum density $\left(\times 10^{3}\right.$ spores $\left.\mathrm{ml}^{-1}\right)$ and FHB Index $(\%)$

Fig. 2. A and B, Mean Fusarium-damaged kernels; C, arcsine-transformed Fusarium-damaged kernels (arcFDK); D and E, deoxynivalenol grain content; F, log-transformed deoxynivalenol grain content (logDON); G, H, and I, test weight; and J, K, and L, yield for grain harvested with different combine harvester configurations from plots with different mean levels of Fusarium head blight index resulting from inoculations with different Fusarium graminearum inoculum densities in 2009 and 2010 . The column of graphs on the right $(\mathbf{C}, \mathbf{F}, \mathbf{I}$, and $\mathbf{L})$ represents the data pooled across the two years. $\mathbf{C} 1=$ the standard setting, with a fan speed of 1,375 rpm and a shutter opening of $70 \mathrm{~mm}$; $\mathrm{C} 2=$ high fan speed $(1,475 \mathrm{rpm})$, with standard shutter opening of $70 \mathrm{~mm} ; \mathrm{C} 3=$ high fan speed $(1,475 \mathrm{rpm})$ and wide shutter opening of $90 \mathrm{~mm}$; and $\mathrm{C} 4=$ standard fan speed $(1,375 \mathrm{rpm})$ and wide shutter opening of $90 \mathrm{~mm}$. 
FDK and DON generally increasing and yield and TW decreasing with increasing inoculum density, for any given combine configuration. Mean FDK ranged from 1.3 to 23.3 and 2.7 to $16 \%$; mean DON from 1.3 to 16.9 and 0.9 to $3.0 \mathrm{ppm}$; and mean TW from 600.3 to 674.7 and 579.0 to $682.9 \mathrm{~kg} / \mathrm{m}^{3}$, in 2009 and 2010 , respectively. Mean grain yield ranged from 1,270 to $2,819 \mathrm{~kg} / \mathrm{ha}$ in 2009 and from 2,630 to 3,536 kg/ha in 2010. Effects of combine configuration were more complex, with $\mathrm{C} 3$ generally having lower DON, FDK, and yield and higher TW than the other configurations, at any given level of disease (Fig. 2).

For arcFDK and $\log$ DON of the pooled data (Fig. 2C and F), the main effects of inoculum density and combine configuration were statistically significant but the interaction between the two was not (Table 1). The effect of YEAR was not statistically significant. Averaged across combine configurations, grain harvested from inoculated plots had significantly higher mean arcFDK and logDON than the uninoculated check (Fig. 2C and F). Averaged across inoculum density, all modified configurations ( $\mathrm{C} 2, \mathrm{C} 3$, and $\mathrm{C} 4)$ had significantly lower mean arcFDK than the standard (C1; Table 2). Among the modified configurations, both $\mathrm{C} 3$ and $\mathrm{C} 4$ had significantly lowest mean arcFDK than $\mathrm{C} 2$; however, $\mathrm{C} 3$ and $\mathrm{C} 4$ were not significantly different from each other (Table 2). Similarly, with the exception of $\mathrm{C} 2$, averaged across inoculum density, all modified configurations had significantly lower logDON than $\mathrm{C} 1(P$ $<0.05$ ), and C3 was not significantly different from C4 (Table 2).
The effect of the covariate (continuous variable), IND, was statically significant for both arcFDK and $\operatorname{logDON}$ (Table 1). Results from a preliminary analysis of the data showed that the interaction between combine configuration and IND was not statistically significant for the $\operatorname{arcFDK}(P=0.494)$ and $\operatorname{logDON}(P=0.660)$ responses; therefore, a common-slope model (without the configuration-IND interaction term) was fitted to the data for these responses, with a separate intercept estimated for each combine configuration (Table 3; Fig. 3). Based on mean differences between the heights of the regression lines for relationships between arcFDK and IND and $\log D O N$ and IND, all modified configurations $(\mathrm{C} 2, \mathrm{C} 3$, and $\mathrm{C} 4)$ had significantly lower arcFDK than standard configuration $\mathrm{C} 1$, whereas only $\mathrm{C} 3$ and $\mathrm{C} 4$ had significantly lower $\log$ DON than the standard (Table 4). C3 and C4 also had significantly lower arcFDK and $\log \mathrm{DON}$ than $\mathrm{C} 2$; however, the difference in intercepts between $\mathrm{C} 3$ and $\mathrm{C} 4$ was not statistically significant for either of the two responses.

The main effect of combine configuration and its interaction with inoculum density were statistically significant for TW and yield (Table 1) but the main effect of inoculum density was not. The effect of YEAR was not statistically significant for these two responses. The effect of combine configuration on TW and grain yield varied with inoculum density based on the significant interaction (Tables 1 and 2). All modified configurations (C2, C3, and C4) had significantly higher TWs than the standard configuration in the

Table 2. Probability values (significance levels) for pairwise comparisons between combine harvester configurations from linear mixed model analyses of the effects of Gibberella zeae inoculum density and combine harvester configuration on arcsine-transformed Fusarium-damaged kernel (arcFDK), log-transformed deoxynivalenol contamination of harvested grain $(\log D O N)$, test weight $(\mathrm{TW})$, and grain yield for data pooled across years 2009 and 2010

\begin{tabular}{|c|c|c|c|c|}
\hline Contrasts $^{\mathrm{a}}$ & $\operatorname{arcFDK}^{\mathbf{b}}$ & $\log D O N^{c}$ & TW $^{\mathrm{d}}$ & Grain yield $^{\mathrm{e}}$ \\
\hline $\mathrm{C} 1$ vs. $\mathrm{C} 2$ & 0.010 & 0.701 & $\ldots$ & $\ldots$ \\
\hline $\mathrm{C} 1$ vs. $\mathrm{C} 3$ & $<0.001$ & 0.001 & $\ldots$ & $\ldots$ \\
\hline $\mathrm{C} 1$ vs. $\mathrm{C} 4$ & $<0.001$ & 0.001 & $\ldots$ & $\ldots$ \\
\hline $\mathrm{C} 2$ vs. C3 & 0.009 & 0.001 & $\ldots$ & $\ldots$ \\
\hline $\mathrm{C} 2$ vs. $\mathrm{C} 4$ & 0.007 & 0.002 & $\ldots$ & $\ldots$ \\
\hline C3 vs. C4 & 0.885 & 0.849 & $\ldots$ & 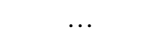 \\
\hline $\mathrm{C} 1$ vs. $\mathrm{C} 2$ at $\mathrm{INOC} 1$ & $\ldots$ & $\ldots$ & 0.001 & 0.039 \\
\hline $\mathrm{C} 1$ vs. $\mathrm{C} 3$ at $\mathrm{INOC} 1$ & $\ldots$ & $\ldots$ & $<0.001$ & 0.075 \\
\hline $\mathrm{C} 1$ vs. $\mathrm{C} 4$ at $\mathrm{INOC} 1$ & $\ldots$ & $\ldots$ & $<0.001$ & 0.325 \\
\hline $\mathrm{C} 2$ vs. $\mathrm{C} 3$ at INOC 1 & $\ldots$ & $\ldots$ & 0.610 & $<0.001$ \\
\hline $\mathrm{C} 2$ vs. $\mathrm{C} 4$ at $\mathrm{INOC} 1$ & $\ldots$ & $\ldots$ & 0.675 & 0.003 \\
\hline $\mathrm{C} 3$ vs. $\mathrm{C} 4$ at $\mathrm{INOC} 1$ & $\ldots$ & $\ldots$ & 0.928 & 0.421 \\
\hline $\mathrm{C} 1$ vs. $\mathrm{C} 2$ at $\mathrm{INOC} 2$ & $\ldots$ & $\ldots$ & 0.388 & 0.312 \\
\hline $\mathrm{C} 1$ vs. $\mathrm{C} 3$ at $\mathrm{INOC} 2$ & $\ldots$ & $\ldots$ & 0.143 & $<0.001$ \\
\hline $\mathrm{C} 1$ vs. $\mathrm{C} 4$ at INOC2 & $\ldots$ & $\ldots$ & 0.730 & 0.001 \\
\hline $\mathrm{C} 2$ vs. $\mathrm{C} 3$ at INOC2 & $\ldots$ & $\ldots$ & 0.021 & $<0.001$ \\
\hline $\mathrm{C} 2$ vs. $\mathrm{C} 4$ at INOC2 & $\ldots$ & $\ldots$ & 0.228 & 0.021 \\
\hline $\mathrm{C} 3$ vs. $\mathrm{C} 4$ at $\mathrm{INOC} 2$ & $\ldots$ & $\ldots$ & 0.259 & 0.170 \\
\hline $\mathrm{C} 1$ vs. $\mathrm{C} 2$ at INOC 3 & $\ldots$ & $\ldots$ & 0.363 & 0.847 \\
\hline $\mathrm{C} 1$ vs. $\mathrm{C} 3$ at INOC 3 & $\ldots$ & $\ldots$ & $<0.001$ & 0.004 \\
\hline $\mathrm{C} 1$ vs. $\mathrm{C} 4$ at INOC 3 & $\ldots$ & $\ldots$ & 0.001 & 0.735 \\
\hline $\mathrm{C} 2$ vs. $\mathrm{C} 3$ at INOC 3 & $\ldots$ & $\ldots$ & 0.005 & 0.007 \\
\hline $\mathrm{C} 2$ vs. $\mathrm{C} 4$ at INOC3 & $\ldots$ & $\ldots$ & 0.019 & 0.596 \\
\hline $\mathrm{C} 3$ vs. $\mathrm{C} 4$ at INOC 3 & $\ldots$ & $\ldots$ & 0.620 & 0.002 \\
\hline $\mathrm{C} 1$ vs. $\mathrm{C} 2$ at INOC4 & $\ldots$ & $\ldots$ & 0.025 & 0.061 \\
\hline $\mathrm{C} 1$ vs. $\mathrm{C} 3$ at INOC 4 & $\ldots$ & $\ldots$ & $<0.001$ & $<0.001$ \\
\hline $\mathrm{C} 1$ vs. $\mathrm{C} 4$ at INOC4 & $\ldots$ & $\ldots$ & $<0.001$ & 0.086 \\
\hline $\mathrm{C} 2$ vs. $\mathrm{C} 3$ at INOC4 & $\ldots$ & $\ldots$ & 0.094 & $<0.001$ \\
\hline $\mathrm{C} 2$ vs. $\mathrm{C} 4$ at INOC4 & $\ldots$ & $\ldots$ & 0.083 & 0.873 \\
\hline C3 vs. C4 at INOC4 & $\ldots$ & $\ldots$ & 0.955 & $<0.001$ \\
\hline $\mathrm{C} 1$ vs. $\mathrm{C} 2$ at INOC5 & $\ldots$ & $\ldots$ & 0.003 & 0.391 \\
\hline $\mathrm{C} 1$ vs. $\mathrm{C} 3$ at INOC5 & $\ldots$ & $\ldots$ & $<0.001$ & 0.002 \\
\hline $\mathrm{C} 1$ vs. $\mathrm{C} 4$ at INOC5 & $\ldots$ & $\ldots$ & $<0.001$ & 0.011 \\
\hline $\mathrm{C} 2$ vs. $\mathrm{C} 3$ at INOC5 & $\ldots$ & $\ldots$ & 0.080 & 0.026 \\
\hline $\mathrm{C} 2$ vs. $\mathrm{C} 4$ at $\mathrm{INOC} 5$ & $\ldots$ & $\ldots$ & 0.140 & 0.090 \\
\hline $\mathrm{C} 3$ vs. $\mathrm{C} 4$ at INOC5 & $\ldots$ & $\ldots$ & 0.780 & 0.590 \\
\hline
\end{tabular}

${ }^{\mathrm{a}}$ INOC1, INOC2, INOC3, INOC4, and INOC5 = inoculum densities of 0, 15, 30, 45, and $60 \times 10^{3}$ spores $\mathrm{ml}^{-1}$; $\mathrm{C} 1=$ the standard configuration, with a fan speed of $1,375 \mathrm{rpm}$ and a shutter opening of $70 \mathrm{~mm} ; \mathrm{C} 2=$ a high fan speed of $1,475 \mathrm{rpm}$, with a shutter opening of $70 \mathrm{~mm} ; \mathrm{C} 3=\mathrm{a}$ fan speed of $1,475 \mathrm{rpm}$ and a shutter opening $90 \mathrm{~mm}$; and $\mathrm{C} 4=\mathrm{a}$ fan speed of $1,375 \mathrm{rpm}$ and a shutter opening of $90 \mathrm{~mm}$.

${ }^{\mathrm{b}} \mathrm{FDK}=$ percentage of visually diseased kernels.

${ }^{c}$ Grain weight per unit volume $\left(\mathrm{kg} / \mathrm{m}^{2}\right)$.

${ }^{\mathrm{d}} \mathrm{DON}=$ deoxynivalenol content of grain $(\mathrm{ppm})$.

e Yield $=$ grain yield $(\mathrm{kg} / \mathrm{ha})$. 
uninoculated check $\left(0 \times 10^{3}\right.$ spores $\left./ \mathrm{ml}\right)$ and at the two highest inoculum densities ( 45 and $60 \times 10^{3}$ spores $/ \mathrm{ml}$ ); however, only C3 and $\mathrm{C} 4$ had significantly higher TWs than $\mathrm{C} 1$ at $30 \times 10^{3}$ spores $/ \mathrm{ml}$, and none of the modified configurations were significantly different from the standard at $15 \times 10^{3} \mathrm{spore} / \mathrm{ml}$ (Table 2; Fig. 2I). Results from a preliminary covariance analysis of the TW data with FHB IND as a covariate showed that the combine configuration-IND interaction was not statistically significant, indicating that the slope for the TW-IND relationship did not vary with combine configuration (i.e., effect of combine configuration on TW was consistent across IND levels). Therefore, a common-slope model was fitted to the data and the estimated differences between the heights of the regression lines (i.e., differences in intercepts) were statistically significant for all pairwise comparisons between combine configurations, except for the comparison between $\mathrm{C} 3$ and $\mathrm{C} 4$, the configurations with the highest mean TWs (Table 4).

In general, modified configurations had lower mean grain yield than the standard configuration. C3 had significantly lower yield than $\mathrm{C} 1$ at all inoculum densities other than the uninoculated check $\left(0 \times 10^{3}\right.$ spores $\left./ \mathrm{ml}\right)$, whereas $\mathrm{C} 4$ had significantly lower yield than $\mathrm{C} 1$ at $60 \times 10^{3}$ and $15 \times 10^{3}$ spores $/ \mathrm{ml}$ but not at $30 \times 10^{3}$ and $45 \times$ $10^{3}$ spores $/ \mathrm{ml}$ (Table 2 ). On the other hand, $\mathrm{C} 2$ yield was only significantly different from $\mathrm{C} 1$ yield for the uninoculated check but not for any other inoculum densities (Table 2; Fig. 2L). After fitting a common-slope covariance model to the yield/IND data, results showed that the yield/IND regression line was significantly higher for $\mathrm{C} 1$ than $\mathrm{C} 3$ and $\mathrm{C} 4$ but not $\mathrm{C} 2$, higher for $\mathrm{C} 2$ than $\mathrm{C} 3$ and $\mathrm{C} 4$, and higher for C4 than C3 (Table 4). In other words, the configuration with the widest shutter opening and higher fan speed (greatest volume of air flowing through the system) resulted in the lowest amounts of harvested grain per hectare.

Cost/benefit assessment. Through the use of equations 1 and 2, the tradeoff of yield and grain quality can be quantified for our results with the different combine settings. The three discount components of the $d c t$ variable in equation 2 ( $t w l, f d k l$, and $d o n l)$ were determined using an example schedule in Table 5 (M. McMullen, personal communication), based on the predicted TW, FDK, and DON from the mixed model. For instance, with a predicted DON of $2 \mathrm{ppm}$, there would be a discount of $\$ 0.05 / \mathrm{bu}$ or $\$ 1.97 / \mathrm{t}$. The total discount was then determined as the sum of the individual discounts for the particular combination of IND and combine configuration. For instance, consider the last row in Table 6: $d c t=\$ 71.27 /$ t. For three grain prices, the GCI was then estimated based on equation 1 . Grain harvested with the standard configuration $(\mathrm{C} 1)$ received higher estimated price discounts compared with the other configurations at all tested levels of mean IND (Table 6). C3 and C4 consistently had the lowest estimated discounts in prices at all three IND levels (Table 6). The differences in total price discounts between $\mathrm{C} 1$ and the other configurations varied with disease level. For instances, the difference in total discount between $\mathrm{C} 1$ and $\mathrm{C} 2, \mathrm{C} 1$ and $\mathrm{C} 3$, and $\mathrm{C} 1$ and $\mathrm{C} 4$ at $5 \%$ IND were $\$ 10.23,19.63$, and $18.10 / \mathrm{t}$, respectively; at the highest level of
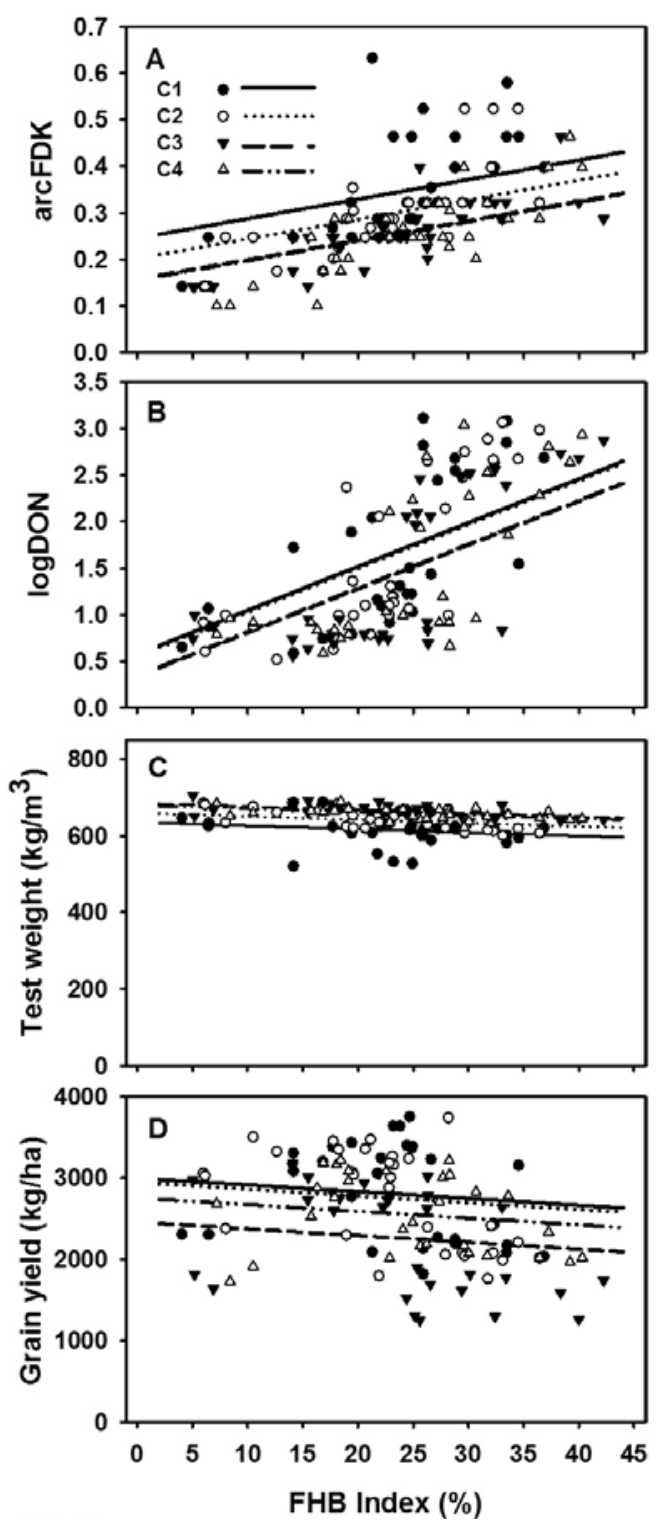

Fig. 3. Relationship between A, arcsine-transformed Fusarium-damaged kernel (arcFDK); B, log-transformed deoxynivalenol content of grain $(\operatorname{logDON})$; C, test weight; and $\mathbf{D}$, grain yield and Fusarium head blight $(\mathrm{FHB})$ index for four combine harvest configurations used to harvest grain from FHB-affected plots: $\mathrm{C} 1=$ the standard setting, with a fan speed of $1,375 \mathrm{rpm}$ and a shutter opening of $70 \mathrm{~mm}$; $\mathrm{C} 2=$ high fan speed $(1,475 \mathrm{rpm})$, with standard shutter opening of $70 \mathrm{~mm} ; \mathrm{C} 3=$ high fan speed $(1,475 \mathrm{rpm})$ and wide shutter opening of $90 \mathrm{~mm}$; and $\mathrm{C} 4=$ standard fan speed $(1,375 \mathrm{rpm})$ and wide shutter opening of $90 \mathrm{~mm}$. Points represent data from three replications and 2 years for each combine configuration. Lines are based on regression parameters from a linear mixed-model covariance analysis.

Table 3. Estimated intercepts and slopes and their corresponding standard errors (SEs) for relationships between arcsine-transformed Fusarium-damaged kernels $(\operatorname{arcFDK}), \log$-transformed deoxynivalenol $(\log D O N)$, test weight and grain yield, and Fusarium head blight (FHB) index (IND) of wheat for four different combine harvester configurations

\begin{tabular}{|c|c|c|c|c|c|c|c|c|}
\hline \multirow[b]{3}{*}{ Factor $^{\mathbf{b}}$} & \multicolumn{8}{|c|}{ Response variable $^{\mathbf{a}}$} \\
\hline & \multicolumn{2}{|c|}{$\operatorname{arcFDK}(\%)$} & \multicolumn{2}{|c|}{$\operatorname{logDON}(\mathbf{p p m})$} & \multicolumn{2}{|c|}{ Test weight $\left(\mathbf{k g} / \mathbf{m}^{\mathbf{3}}\right)$} & \multicolumn{2}{|c|}{ Grain yield (kg/ha) } \\
\hline & Intercept & SE & Intercept & SE & Intercept & SE & Intercept & SE \\
\hline $\mathrm{C} 1$ & 0.246 & 0.033 & 0.577 & 0.542 & 635.07 & 11.21 & $2,996.11$ & 499.61 \\
\hline $\mathrm{C} 2$ & 0.202 & 0.032 & 0.555 & 0.542 & 659.38 & 11.18 & $2,941.41$ & 499.46 \\
\hline C3 & 0.157 & 0.033 & 0.335 & 0.542 & 684.99 & 11.34 & $2,454.76$ & 500.20 \\
\hline C4 & 0.155 & 0.034 & 0.346 & 0.543 & 679.57 & 11.61 & $2,752.70$ & 501.40 \\
\hline Slope $(\mathrm{SE})^{\mathrm{c}}$ & \multicolumn{2}{|c|}{$0.004(0.001)$} & \multicolumn{2}{|c|}{$0.047(0.005)$} & \multicolumn{2}{|c|}{$-0.877(0.346)$} & \multicolumn{2}{|c|}{$-8.320(4.873)$} \\
\hline
\end{tabular}

a Predictor variable was FHB IND (\%). Intercept estimated from linear mixed-model covariance analysis.

${ }^{\mathrm{b}}$ Combine harvest configurations used to harvest grain from FHB-affected plots: $\mathrm{C} 1=$ the standard setting, with a fan speed of $1,375 \mathrm{rpm}$ and a shutter opening of $70 \mathrm{~mm} ; \mathrm{C} 2=$ high fan speed $(1,475 \mathrm{rpm})$, with standard shutter opening of $70 \mathrm{~mm} ; \mathrm{C} 3=$ high fan speed $(1,475 \mathrm{rpm})$ and wide shutter opening of 90 $\mathrm{mm}$; and $\mathrm{C} 4=$ standard fan speed $(1,375 \mathrm{rpm})$ and wide shutter opening of $90 \mathrm{~mm}$.

${ }^{\mathrm{c}}$ Common slope estimated from linear mixed-model covariance analysis. 
disease (35\% IND), however, the corresponding differences were $\$ 12.15,40.10$, and $38.52 / \mathrm{t}$, respectively.

In general, as expected, at any given grain price, the highest and lowest GCIs were observed at the lowest and highest tested levels of IND, respectively. Comparing the combine configurations, the highest GCIs were estimated at the low IND value (5\%) for grain harvested with configurations $\mathrm{C} 2$ and $\mathrm{C} 4$ (Table 6). This ranking was maintained at all tested grain prices. At the highest tested IND value $(35 \%)$ and lowest tested grain prices, GCI was highest for grain harvested with configurations $\mathrm{C} 3$ and $\mathrm{C} 4$ (Table 6). The relatively high GCI for $\mathrm{C} 3$ at this level of disease was not maintained at the highest grain price. At the highest price evaluated $(\$ 276 / t)$, C3 gave the lowest GCI $(\$ 446.36 / \mathrm{ha})$. C4 was the most consistent combine configuration, with the highest GCI in seven of the nine grain price-IND scenarios evaluated (Table 6). Across disease levels and grain prices, grain harvested with $\mathrm{C} 4$ resulted in one of the top two estimated GCIs per hectare for all scenarios, except for the combination of lowest IND (5\%) and highest grain price (\$276/t) evaluated. C2 resulted in the highest GCI for one and the second highest for four of the nine scenarios. In general, based on GCI, the $\mathrm{C} 3$ combine configuration was inferior to $\mathrm{C} 4$ in all cases and was only superior to $\mathrm{C} 2$ at the two lower grain prices and the highest evaluated levels of FHB.

\section{Discussion}

Our findings constitute the first report of a formal assessment of the cost and benefit of using modified combine harvester con- figurations to harvest grain from FHB-affected fields. We found significant differences in multiple components of grain quality (TW, DON, and FDK) and yield between samples harvested with the standard and those harvested with the modified combine configurations considered in this study. Grain harvested with modified configurations (higher fan speed and air flow through the system; $\mathrm{C} 2, \mathrm{C} 3$, and C4) had significantly lower FDK and DON than the standard (C1) across a range of mean FHB IND levels. For instances, configuration $\mathrm{C} 3$ and $\mathrm{C} 4$ consistently resulted in the lowest mean FDK and DON levels when compared with configuration $\mathrm{C} 1$. Furthermore, modifying combine configurations also significantly increased the TW of grain lots harvested from plots with intermediate levels of FHB IND. However, the configurations (C3 and $\mathrm{C} 4$ ) that resulted in the greatest gain in grain quality also resulted in significant reductions in the volume or weight of harvested grain. Our results were consistent with those from a similar study conducted in Canada (H. Spieser and A. W. Schaafsma, personal communication), which also showed that grain quality was increased by increasing the fan speed of the harvester; however, this modification resulted to a substantial loss of healthy grain.

Because FDKs are smaller and lighter than healthy-looking kernels $(14,20)$, many were apparently physically removed when plots were harvested with the combine adjusted to a fan speed and volume of air flow higher than the standard configuration. In addition, because the levels of FDK are often highly correlated with DON levels $(3,6,30)$, removing FDK and smaller and lighter kernels in

Table 4. Least square differences (Diff) in the heights of regression lines for relationships between arcsine-transformed Fusarium-damaged kernels (arcFDK), log-transformed deoxynivalenol $(\log \mathrm{DON})$, test weight, and grain yield and Fusarium head blight (FHB) index (IND) for pairwise comparisons between combine harvester configurations

\begin{tabular}{|c|c|c|c|c|c|c|c|c|c|c|c|c|}
\hline \multirow[b]{3}{*}{ Contrasts $^{b}$} & \multicolumn{12}{|c|}{ Response variable ${ }^{a}$} \\
\hline & \multicolumn{3}{|c|}{$\operatorname{arcFDK}(\%)$} & \multicolumn{3}{|c|}{$\operatorname{logDON}(\mathbf{p p m})$} & \multicolumn{3}{|c|}{ Test weight $\left(\mathrm{kg} / \mathrm{m}^{\mathbf{3}}\right)$} & \multicolumn{3}{|c|}{ Grain yield (kg/ha) } \\
\hline & Diff & SE & $P$ & Diff & SE & $P$ & Diff & SE & $P$ & Diff & SE & $P$ \\
\hline $\mathrm{C} 1$ vs. $\mathrm{C} 2$ & 0.044 & 0.015 & 0.010 & 0.021 & 0.055 & 0.701 & -24.31 & 10.58 & 0.036 & 54.69 & 65.07 & 0.414 \\
\hline $\mathrm{C} 1$ vs. C3 & 0.088 & 0.015 & $<0.001$ & 0.241 & 0.055 & 0.001 & -49.92 & 10.59 & $<0.001$ & 541.34 & 65.12 & $<0.001$ \\
\hline $\mathrm{C} 1$ vs. $\mathrm{C} 4$ & 0.090 & 0.015 & $<0.001$ & 0.231 & 0.055 & 0.001 & -44.51 & 10.60 & 0.001 & 243.41 & 65.53 & 0.002 \\
\hline C2 2 vs. C3 & 0.045 & 0.015 & 0.009 & 0.220 & 0.055 & 0.001 & -25.61 & 10.59 & 0.029 & 486.65 & 65.15 & $<0.001$ \\
\hline C2 vs. C4 & 0.047 & 0.015 & 0.007 & 0.209 & 0.055 & 0.002 & -20.20 & 10.60 & 0.076 & 188.71 & 65.62 & 0.012 \\
\hline $\mathrm{C} 3$ vs. $\mathrm{C} 4$ & 0.002 & 0.015 & 0.885 & -0.011 & 0.055 & 0.849 & 5.41 & 10.59 & 0.617 & -297.94 & 65.28 & $<0.001$ \\
\hline
\end{tabular}

${ }^{a}$ Predictor variable $=$ FHB IND $(\%)$, SE $=$ standard error of the difference, and $P=$ probability values for the estimated differences in arcFDK, logDON, test weight, and yield.

${ }^{\mathrm{b}}$ Combine harvest configurations used to harvest grain from FHB-affected plots: $\mathrm{C} 1=$ the standard setting, with a fan speed of 1,375 rpm and a shutter opening of $70 \mathrm{~mm}$; $22=$ high fan speed $(1,475 \mathrm{rpm})$, with standard shutter opening of $70 \mathrm{~mm} ; \mathrm{C} 3=$ high fan speed $(1,475 \mathrm{rpm})$ and wide shutter opening of 90 $\mathrm{mm}$; and $\mathrm{C} 4=$ standard fan speed $(1,375 \mathrm{rpm})$ and wide shutter opening of $90 \mathrm{~mm}$.

Table 5. Sample grain elevator discount schedule for wheat due to test weight, Fusarium-damaged kernels (FDK), and deoxynivalenol (DON) contamination of grain ${ }^{\mathrm{a}}$

\begin{tabular}{|c|c|c|c|c|c|c|c|c|c|}
\hline \multirow[b]{3}{*}{$\mathbf{l b} / \mathbf{b u}$} & \multicolumn{3}{|c|}{ Test weight } & \multicolumn{3}{|c|}{ FDK } & \multicolumn{3}{|c|}{ DON } \\
\hline & \multirow[b]{2}{*}{$\mathrm{kg} / \mathrm{m}^{3}$} & \multicolumn{2}{|c|}{ Discount } & \multirow[b]{2}{*}{$\%$} & \multicolumn{2}{|c|}{ Discount } & \multirow[b]{2}{*}{ ppm } & \multicolumn{2}{|c|}{ Discount } \\
\hline & & $\$ /$ bu & $\$ / t$ & & $\$ / \mathbf{b u}$ & $\$ / t$ & & \$/bu & $\$ / t$ \\
\hline 58.0 & 746.57 & 0.00 & 0.00 & 0.9 & 0.00 & 0.00 & 0.0 & 0.00 & 0.00 \\
\hline 57.5 & 740.13 & 0.04 & 1.57 & 1.0 & 0.02 & 0.79 & 2.0 & 0.05 & 1.97 \\
\hline 57.0 & 733.70 & 0.08 & 3.15 & 1.5 & 0.06 & 2.36 & 2.5 & 0.10 & 3.94 \\
\hline 56.0 & 720.82 & 0.16 & 6.30 & 2.0 & 0.10 & 3.94 & 3.0 & 0.20 & 7.87 \\
\hline 55.0 & 707.95 & 0.24 & 9.45 & 3.0 & 0.13 & 5.12 & 3.5 & 0.30 & 11.81 \\
\hline 54.0 & 695.08 & 0.32 & 12.60 & 4.0 & 0.16 & 6.30 & 4.0 & 0.40 & 15.75 \\
\hline 53.0 & 682.21 & 0.40 & 15.75 & 5.0 & 0.21 & 8.27 & 4.5 & 0.50 & 19.69 \\
\hline 52.0 & 669.34 & 0.48 & 18.90 & 6.0 & 0.26 & 10.24 & 5.0 & 0.60 & 23.62 \\
\hline 51.0 & 656.46 & 0.56 & 22.05 & 7.0 & 0.31 & 12.20 & 6.0 & 0.80 & 31.50 \\
\hline 50.0 & 643.59 & 0.64 & 25.20 & 8.0 & 0.36 & 14.17 & 7.0 & 1.00 & 39.37 \\
\hline 49.0 & 630.72 & 0.72 & 28.35 & 9.0 & 0.41 & 16.14 & 8.0 & 1.20 & 47.24 \\
\hline 48.0 & 617.85 & 0.80 & 31.50 & 10.0 & 0.46 & 18.11 & 9.0 & 1.40 & 55.12 \\
\hline 47.0 & 604.98 & 0.88 & 34.65 & 11.0 & 0.51 & 20.08 & 10.0 & 1.60 & 62.99 \\
\hline 46.0 & 592.11 & 0.96 & 37.80 & 12.0 & 0.56 & 22.05 & 11.0 & 1.80 & 70.87 \\
\hline 45.0 & 579.23 & 1.04 & 40.94 & 13.0 & 0.61 & 24.02 & 12.0 & 2.00 & 78.74 \\
\hline
\end{tabular}

${ }^{a}$ Price discounts were estimated using $746.57 \mathrm{~kg} / \mathrm{ha}$ (58 lb/bushel), $1 \%$, and $2 \mathrm{ppm}$ as grain quality thresholds for test weight, FDK, and DON, respectively. Grain with FDK and DON below and test weight above these thresholds will not receive price discounts. Price discount schedules vary from year to year and from one grain elevator to another. (Source: Courtesy of Dr. M. McMullen, North Dakota State University.) 
general may have contributed to the reduction in the overall DON contamination of grain from plots harvested with the modified configurations. Reducing FDK and other low-density kernels also may have led to an increase in TW by reducing the relative proportion of small, light-weight kernels per unit volume of grain.

Although the effect of inoculum density on response variables was not always consistent, results from the analyses of covariance showed that the magnitude of any given mean (estimated expected) response to combine configuration and difference in mean response between configurations were consistent across observed disease IND levels. That is, there was a common slope (for each response) across the combine configurations. This is likely because IND could have a complex relationship with inoculum density (37). Our findings suggested that the degree to which a modified configuration changed mean FDK, DON, and other responses over the standard did not change with disease intensity within the range tested. Thus, the capacity of the combine modifications to improve the quality of grain harvested from FHB-affected plots, broadly speaking, did not seem to depend on the level of FHB. The relative ratio of FDK to healthy kernels in the harvested grain is known to be directly related to disease IND in the field (30,31), and the overall mean FDK and DON (or other response variables) in this study did, indeed, vary with IND, as was made evident by the slopes of the regression lines in the mixed models. However, our results suggested that the different responses to combine configurations were independent of the proportion of diseased kernels within the grain lot for the range of mean IND observed in this study (5 to 35\%).

The fact that the combine configurations with high fan speed and wide shutter opening (C3 and C4) had lower grain yields than the standard is not surprising. At harvest, combine harvesters are usually calibrated to minimize the loss of normal grain of a certain size and weight, depending on the cultivar and the growing conditions. Hence, deviations from the standard configuration, such as increasing the air flow through the cleaning device (as was the case with $\mathrm{C} 3$ and $\mathrm{C} 4$ ), increased the amount of healthy-looking kernels discarded, reducing the amount of grain harvested. Nevertheless, our results showed that, depending on grain price and the level of FHB intensity, the gain in grain quality with modified combine configurations was generally sufficient to offset the reduction in grain yield, especially with C4 (a fan speed of 1,375 rpm and a shutter opening of $90 \mathrm{~mm}$ ). In fact, changing the combine setting could make the difference between getting grain sold (even at a reduced price) or completely rejected.

The economic analysis, which utilized yield and grain-quality means for the current investigation, coupled with a wide range of grain prices and price discounts (based on FDK, DON, and TW), put all wheat response measurements on the same monetary scale, allowing for direct assessment of tradeoffs in the combine settings. Because of higher grain quality, price discounts were between $\$ 10.00$ and 40.00/t lower with the modified configurations (C2, $\mathrm{C} 3$, and $\mathrm{C} 4)$ compared with the standard (C1), depending on disease IND (and the corresponding values of TW, FDK, and DON), resulting in higher prices being received per kilogram of harvested grain. Consequently, even though the mean grain yield was lower for $\mathrm{C} 4$ than for $\mathrm{C} 1$, this configuration consistently had one of the highest estimated GCIs for a range of FHB levels and grain prices under our cultivar and environmental conditions. For all modified configurations, the gain in GCI over the standard tended to be higher at higher disease intensities and lower grain prices. For instance, at IND between 20 and $35 \%$ and a grain price of $\$ 118 / \mathrm{t}$, GCI was $\$ 25$ to $93 /$ ha higher for C2, C3, and C4 than C1; however, at these same levels of disease, the difference in GCI between modified and standard configurations ranged from $\$-51$ to 54 when the grain price was $\$ 276 /$ t. At $5 \%$ disease IND and a grain price of $\$ 276 / t$, there was a reduction in GCI for two of the three modified configurations ( $\mathrm{C} 3$ and $\mathrm{C} 4)$ over the standard. This was because, in our economic model and with realized values of TW, FDK, and DON, the price penalty for not improving the grain quality represented a smaller proportion of the grain price at higher prices than at low prices. For instance, at 35\% disease IND and a grain price of $\$ 118 / \mathrm{ha}$, price discounts represented between 59 and $93 \%$ of the grain price whereas, at $5 \%$ IND and a grain price of $\$ 276 /$ ha, price discounts represented only 8 to $15 \%$ of the grain price.

Changing combine harvest configurations to increase the speed and volume of air flowing through the system did, indeed, improve grain quality and, consequently, reduced price discounts that would be imposed based on levels of TW, FDK, and DON. However, the estimated economic benefit of combine adjustment depended on disease IND in the field and grain price, tending to be most beneficial at lower grain prices and intermediate disease intensities. When FHB IND is very low, FDK and DON will generally be low, on average $(30,31)$, and the gain in grain quality would probably not be sufficient to offset the reduction in grain yield with modified combine configurations. On the other hand, when FHB intensity is very high (e.g., IND > 50\%), FDK and DON content will generally be high. Thus, even a large reduction in FDK or DON would still result in large values for FDK and DON, on average, and price discounts would remain high. Hence, harvester adjustments would not adequately reduce price discounts to overcome loss in yield.

Table 6. Cost/benefit assessment of using modified combine harvester configurations to harvest grain from Fusarium head blight (FHB)-affected wheat plots for different combinations of mean FHB index (IND) and grain prices ${ }^{\mathrm{a}}$

\begin{tabular}{|c|c|c|c|c|c|c|c|c|c|}
\hline \multirow[b]{2}{*}{ IND } & \multirow[b]{2}{*}{ CONFIG $^{c}$} & \multirow[b]{2}{*}{ Yield (t/ha) } & \multicolumn{3}{|c|}{ Grain quality } & \multirow[b]{2}{*}{ Discount $(\$ / t)^{d}$} & \multicolumn{3}{|c|}{ GCI (\$/ha)/grain price ${ }^{\text {b }}$} \\
\hline & & & TW $\left(\mathrm{kg} / \mathrm{m}^{3}\right)$ & FDK $(\%)$ & DON (ppm) & & $\$ 118 / \mathrm{t}$ & $\$ 197 / t$ & $\$ 276 / t$ \\
\hline \multirow[t]{4}{*}{5} & $\mathrm{C} 1$ & 2.95 & 630.69 & 6.93 & 1.25 & 40.55 & 228.83 & 462.23 & 695.64 \\
\hline & $\mathrm{C} 2$ & 2.90 & 655.00 & 4.88 & 1.20 & 30.32 & 254.26 & 483.34 & 712.43 \\
\hline & $\mathrm{C} 3$ & 2.41 & 680.61 & 3.14 & 0.77 & 20.87 & 234.39 & 425.03 & 615.67 \\
\hline & $\mathrm{C} 4$ & 2.71 & 675.19 & 3.06 & 0.79 & 22.45 & 259.05 & 473.22 & 687.40 \\
\hline \multirow[t]{4}{*}{20} & $\mathrm{C} 1$ & 2.83 & 617.54 & 10.46 & 3.57 & 61.42 & 160.11 & 383.65 & 607.20 \\
\hline & $\mathrm{C} 2$ & 2.78 & 641.85 & 7.94 & 3.47 & 51.18 & 185.43 & 404.65 & 623.88 \\
\hline & C3 & 2.29 & 667.46 & 5.70 & 2.59 & 33.08 & 194.33 & 375.11 & 555.89 \\
\hline & $\mathrm{C} 4$ & 2.59 & 662.04 & 5.60 & 2.62 & 34.66 & 215.54 & 419.86 & 624.18 \\
\hline \multirow[t]{4}{*}{35} & $\mathrm{C} 1$ & 2.70 & 604.39 & 14.62 & 8.25 & 109.79 & 22.21 & 235.90 & 449.58 \\
\hline & $\mathrm{C} 2$ & 2.65 & 628.70 & 11.67 & 8.06 & 97.64 & 53.96 & 263.33 & 472.69 \\
\hline & $\mathrm{C} 3$ & 2.16 & 654.31 & 8.96 & 6.27 & 69.69 & 104.52 & 275.44 & 446.36 \\
\hline & $\mathrm{C} 4$ & 2.46 & 648.89 & 8.84 & 6.35 & 71.27 & 115.03 & 309.48 & 503.94 \\
\hline
\end{tabular}

${ }^{a}$ Grain yield and quality measures were estimated at each level of IND based on the regression parameters from a linear mixed-model covariance analysis. $\mathrm{TW}=$ test weight, $\mathrm{FDK}=$ Fusarium-damaged kernels, and DON $=$ deoxynivalenol.

${ }^{\mathrm{b}}$ Gross cash income (GCI) estimated as $G C I=Y \cdot(P-d c t)$, where $Y$ is grain yield, $P$ is grain price, and $d c t=$ total price discount; $d c t=t w l+f d k l+d o n l$, where $t w l, f d k l$, and donl represent price discounts due to test weight below and FDK and DON contamination above thresholds established by grain elevators.

${ }^{\mathrm{c}}$ Combine harvest configurations (CONFIG) used to harvest grain from FHB-affected plots: $\mathrm{C} 1=$ the standard setting, with a fan speed of 1,375 rpm and a shutter opening of $70 \mathrm{~mm} ; \mathrm{C} 2=$ high fan speed $(1,475 \mathrm{rpm})$, with standard shutter opening of $70 \mathrm{~mm}$; $33=$ high fan speed $(1,475 \mathrm{rpm})$ and wide shutter opening of $90 \mathrm{~mm}$; and $\mathrm{C} 4=$ standard fan speed $(1,375 \mathrm{rpm})$ and wide shutter opening of $90 \mathrm{~mm}$.

${ }^{\mathrm{d}}$ Estimated total price discount based on the example discount schedule in Table 5. 
However, at intermediate levels of disease (e.g., IND $=20$ to $35 \%$ ), there is opportunity to have a larger impact on the price discounts that can offset reductions in yield due to modified combine settings. Disease intensity (including INC and IND) varies considerably among individual spikes in a wheat field $(5,24)$ and, especially at intermediate levels of IND, there will be a considerable number of healthy spikes among diseased spikes and healthy spikelets on diseased spikes, ultimately translating into a considerable number of healthy-looking kernels among diseased kernels. Hence, appropriate grain-harvesting techniques to reduce diseased kernels could make the difference between a lot of grain from a field with moderate FHB intensity being accepted or rejected at grain elevators.

The decision to harvest grain from FHB-affected fields with increased combine fan speed and air flow should be based on the expected level of yield and grain price, as well as the expected price discounts based on FDK, TW, and DON, with yield, FDK, TW, and DON all being statistical functions of disease IND (and other variables). The specific modifications needed to achieve a certain air flow will likely vary from one combine to another, and the adjustments made to fan speed and shutter opening in this study should serve as a guide for the protocols to adjust other models of combine harvester. In our case, the fan speeds and shutter openings that gave the highest output air speeds (C3, approximately $30 \mathrm{~km} / \mathrm{h}$; and $\mathrm{C} 4$, approximately $27 \mathrm{~km} / \mathrm{h}$ ) provided, in general, the greatest reduction in FDK and DON and the highest increase in TW over the standard combine settings (C1). However, $\mathrm{C} 4$ was more economically beneficial than $\mathrm{C} 3$ because it resulted in less healthy grain being lost during harvest. Further research is currently in progress to evaluate the cost and benefit of using the C4 settings as part of an integrated management program that includes cultivar resistance and fungicide application. This will allow us to evaluate $\mathrm{C} 4$ across a range of disease levels in cultivars with different grain characteristic to see if these will affect the results. Further work is needed in different environments (or with different wheat market classes) to determine the effects of different statistical relationships between IND and the response variables on the cost and benefit of changing combine configurations to improve grain quality.

\section{Acknowledgments}

Salaries and research support were provided by state and federal funds to the Ohio Agricultural Research and Development Center. This investigation is based upon work supported, in part, by the United States Department of Agriculture (agreement number 59-0206-9-071). This is a cooperative project with the U.S. Wheat \& Barley Scab Initiative. We thank M. McMullen, North Dakota State University, for providing an example discount schedule; A. W. Schaafsma, University of Guelph, for input on modifying combine configuration to harvest infected grain; W. Bardall, R. Barry, and J. Heller for assisting with establishment, maintenance, and harvest of research plots; and G. Nielsen, Client Support Technician, ALMACO, for assisting with combine calibration.

\section{Literature Cited}

1. Bai, G.-H., and Shaner, G. 1994. Scab of wheat: prospects for control. Plant Dis. 78:760-766.

2. Bai, G.-H., and Shaner, G. 2004. Management and resistance in wheat and barley to Fusarium head blight. Annu. Rev. Phytopathol. 42:135-161.

3. Beyer, M., Klix, M., and Verreet, J. 2007. Estimating mycotoxin contents of Fusarium-damaged winter wheat kernels. Int. J. Food Microbiol. 119:153158.

4. Beyer, M., Pogoda, F., Ronellenfitsch, F. K., Hoffmann, and L., Udelhoven, T. 2010. Estimating deoxynivalenol contents of wheat samples containing different levels of Fusarium-damaged kernels by diffuse reflectance spectrometry and partial least square regression. Int. J. Food Microbiol. 142:370-374.

5. Del Ponte, E. M., Shah, D. A., and Bergstrom, G. C. 2003. Spatial patterns of Fusarium head blight in New York wheat fields suggest role of airborne inoculum. Plant Health Progress. Online publication. doi:10.1094/PHP2003-0418-01-RS

6. Delwiche, S. R., Pearson, T. C., and Brabec, D. L. 2005. High-speed optical sorting of soft wheat for reduction of deoxynivalenol. Plant Dis. 89:12141219.

7. Dill-Macky, R., and Jones, R. K. 2000. The effect of previous crop residues and tillage on Fusarium head blight of wheat. Plant Dis. 84:71-76.

8. Edwards, S. G. 2004. Influence of agricultural practices on Fusarium infection of cereals and subsequent contamination of grain by trichothecene mycotoxins. Toxicol. Lett. 153:29-35.
9. Engle, J. S., De Wolf, E. D., and Lipps, P. E. 2000. A visual scale for estimating damage to soft red winter wheat kernels by Fusarium head blight Pages 141-142 in: Proc. Natl. Fusarium Head Blight Forum. K. Y. Erlander, R. W. Ward, S. M. Canty, J. Lewis, and L. Siler, eds. Michigan State University, East Lansing.

10. Engle, J. S., Madden, L. V., and Lipps, P. E. 2003. Evaluation of inoculation methods to determine resistance reactions of wheat to Fusarium graminearum. Plant Dis. 87:1530-1535.

11. Inch, S. A., and Gilbert, J. 2003. Survival of Gibberella zeae in Fusariumdamaged wheat kernels. Plant Dis. 87:282-287.

12. Jouany, J. P. 2007. Methods for preventing, decontaminating and minimizing the toxicity of mycotoxins in feeds. Anim. Feed Sci. Technol. 137:342362.

13. Kriss, A. B., Paul, P. A., and Madden, L. V. 2010. Relationship between yearly fluctuations in Fusarium head blight intensity and environmental variables: a window-pane analysis. Phytopathology 100:784-797.

14. Leonard, K. J., and Bushnell, W. R. 2003. Pages 35-120 in: Fusarium Head Blight of Wheat and Barley. The American Phytopathological Society Press, St. Paul, MN.

15. Littell R. C., Milliken G. A., Stroup W. W., Wolfinger R. D., and Schabenberger O. 2006. SAS for Mixed Models, second ed. SAS Institute, Cary, $\mathrm{NC}$.

16. Lori, G. A., Sisterna M. N., Sarandón, S.J., Rizzo I., and Chidichimo, H. 2009. Fusarium head blight in wheat: impact of tillage and other agronomic practices under natural infection. Crop Prot. 28:495-502.

17. Madden, L. V., and Paul, P. A. 2009. Assessing heterogeneity in the relationship between wheat yield and Fusarium head blight intensity using randomcoefficient mixed models. Phytopathology 99:850-860.

18. Maldonado-Ramirez, S. L., Schmale, D. G., Shields, E. J., and Bergstrom, G. C. 2005. The relative abundance of viable spores of Gibberella zeae in the planetary boundary layer suggests the role of long- distance transport in regional epidemics of Fusarium head blight. Agric. For. Meteorol. 132:2027.

19. McMullen, M. 2007. Experiences in reducing disease and DON through components of FHB management. Pages 102-103 in: Proc. Natl. Fusarium Head Blight Forum, Kansas City, MO. S. M. Canty, A. Clark, D. Ellis, and D. A. Van Sanford, eds. University of Kentucky, Lexington.

20. McMullen M., Jones R., and Gallenberg D. 1997. Scab of wheat and barley: a re-emerging disease of devastating impact. Plant Dis. 81:1340-1348.

21. Mesterházy, Á., Bartók, T., and Lamper, C. 2003. Influence of wheat cultivar, species of Fusarium, and isolate aggressiveness on the efficacy of fungicides for control of Fusarium head blight. Plant Dis. 87:1107-1115.

22. Miedaner, T., Moldovan, M., and Ittu, M. 2003. Comparison of spray and point inoculation to assess resistance to Fusarium head blight in a multienvironment wheat trial. Phytopathology 93:1068-1072.

23. Nishio, Z., Takata, K., Ito, M., Tanio, M., Tabiki, T., Yamauchi, H., and Ban, T. 2010. Deoxynivalenol distribution in flour and bran of spring wheat lines with different levels of Fusarium head blight resistance. Plant Dis. 94:335338.

24. Odenbach, K. J. 2009. Epidemiology and variability of disease and deoxynivalenol in Fusarium head blight of wheat in Ohio. Thesis, The Ohio State University, Wooster.

25. Osborne, L. E., and Stein, J. M. 2007. Epidemiology of Fusarium head blight on small-grain cereals. Int. J. Food Microbiol. 119:103-108.

26. Parry D. W., Jenkinson P., and McLeod L. 1995. Fusarium ear blight (scab) in small grain cereals-a review. Plant Pathol. 44:207-238.

27. Paul, P., Beuerlein, J., Loux, M., Lentz, E., Hammond, R., and Mullen, R 2008. Improving Wheat Profits in Ohio. The Ohio State University/OSUE. Bull. 938.

28. Paul, P. A., Lipps, P. E., Hershman, D. E., McMullen, M. P., Draper, M. A., and Madden, L. V. 2007. A quantitative review of tebuconazole effect on Fusarium head blight and deoxynivalenol content in wheat. Phytopathology 97:211-220.

29. Paul, P. A., Lipps, P. E., Hershman, D. E., McMullen, M. P., Draper, M. A., and Madden, L. V. 2008. Efficacy of triazole-based fungicides for Fusarium head blight and deoxynivalenol control in wheat: a multivariate meta-analysis. Phytopathology 98:999-1011.

30. Paul, P. A., Lipps, P. E., and Madden, L. V. 2005. Relationship between visual estimates of Fusarium head blight intensity and deoxynivalenol accumulation in harvested wheat grain: a meta-analysis. Phytopathology 95:1225-1236.

31. Paul, P. A., Lipps, P. E., and Madden, L. V. 2006. Meta-analysis of regression coefficients for the relationship between Fusarium head blight and deoxynivalenol content of wheat. Phytopathology 96:951-961.

32. Paul, P. A., McMullen, M. P., Hershman, D. E., and Madden, L. V. 2010 Meta-analysis of the effects of triazole-based fungicides on wheat yield and test weight as influenced by Fusarium head blight intensity. Phytopathology 100:160-171.

33. Placinta, C. M., D’Mello, J. P. F., and Macdonald, A. M. C. 1999. A review of worldwide contamination of cereal grains and animal feed with Fusarium mycotoxins. Anim. Feed Sci. Technol. 78:21-37.

34. Ransom, J. K., and McMullen, M. V. 2008. Yield and disease control on hard winter wheat cultivars with foliar fungicides. Agron. J. 100:1130-1137.

35. Schaafsma, A. W., and Tamburic-Ilincic, L. 2005. Effect of seeding rate and 
seed treatment fungicides on agronomic performance, Fusarium head blight symptoms, and DON accumulation in two winter wheats. Plant Dis. 89:1109-1113.

36. Snijders C. H. A. 2004. Resistance in wheat to Fusarium infection and trichothecene formation. Toxicol. Lett. 153:37-46.

37. Stein, J. M., Osborne, L. E., Bondalapati, K. D., Glover, K. D., and Nelson, C. A. 2009. Fusarium head blight severity and deoxynivalenol concentration in wheat in response to Gibberella zeae inoculum concentration. Phytopathology 99:759-764.

38. Tkachuk, R., Dexter, J. E., Tipples, K. H., and Nowicki, T. W. 1991. Removal by specific gravity table of tombstone kernels and associated trichothecenes from wheat infected with Fusarium head blight. Cereal Chem. 68:428-431.

39. Trenholm, H. L., Charmley, L. L., Prelusky, D. B., and Warner, R. M. 1991. Two physical methods for the decontamination of four cereals contaminated with deoxynivalenol and zearalenone. J. Agric. Food Chem. 39:356-360.

40. Václav, S., Ruzek, P., Chrpova, J., Vavera, R., and Kusa, H. 2009. The effect of tillage practice, input level and environment on the grain yield of winter wheat in the Czech Republic. Field Crop Res. 113:131-137.

41. Wegulo, S. N., Bockus, W. W., Hernandez Nopsa, J., De Wolf, E. D., Eskridge, K. M., Peiris, K. H. S., and Dowell, F. E. 2011. Effects of inte- grating cultivar resistance and fungicide application on Fusarium head blight and deoxynivalenol in winter wheat. Plant Dis. 95:554-560.

42. Willyerd, K., Madden, L., Bergstrom, G., Bradley, C., Grybauskas, A., Hershman, D., McMullen, M., Ruden, K., Sweets, L., Wegulo, S., Wise, K., and Paul, P. 2009. Integrated management of FHB and DON in small grains: 2009 coordinated trials. Pages 95-99 in: Proc. Natl. Fusarium Head Blight Forum, Orlando, FL. S. M. Canty, A. Clark, J. Mundell, E. Walton, D. Ellis, and D. A. Van Sanford, eds. University of Kentucky, Lexington.

43. Yang, I-C., Delwiche, S. R., Chen, S., and Lo, Y. M. 2009. Enhancement of Fusarium head blight detection in free-falling wheat kernels using a bichromatic pulsed LED design. Opt. Eng. 48. Online publication. doi:10.1117/ 1.3081092 .

44. Yoshida, M., and Nakajima, T. 2010. Deoxynivalenol and nivalenol accumulation in wheat infected with Fusarium graminearum during grain development. Phytopathology 100:763-773.

45. Young, J. C., Subryan, L. M., Potts, D., McLaren, M. E., and Gobran, F. H 1986. Reduction in levels of deoxynivalenol in contaminated wheat by chemical and physical treatment. J. Agric. Food Chem. 34:461-465.

46. Yuen, G. Y., and Schoneweis, S. D. 2007. Strategies for managing Fusarium head blight and deoxynivalenol accumulation in wheat. Int. J. Food Microbiol. 119:126-130. 